\title{
Visual Communication Design and Research Network forms of Media
}

\author{
Yunling LIU \\ Art Institute \\ Jiujiang University \\ Jiujiang, China
}

\begin{abstract}
Internet media visual communication design combines modern digital technology; visual communication design provides a new means to communicate, a new way of performance, the dual role of creative inspiration and reference. The positive impacts of online media art visual communication designs are visually oriented function; it will promote the perception and memory, as well as to strengthen the visual impact of the information in favor of the audience "filter." But there are also less passive tap, the forum is limited and technology is limited. Network Media in Visual Communication Design focuses mainly in information design and interaction design aspects. Internet media for the arts has brought a new possibility, which provided a new platform for traditional art performance.
\end{abstract}

Keywords- Network Media Arts; Visual Communication Design; Manifestations

\section{INTRODUCTION}

\section{A. The basic features of multimedia art}

The first is the synthesis of art and overall performance. Multimedia art synthesized is as by text, graphics, images, symbols, lines, colors and visual elements, such as the composition of multimedia visual arts and by voice, music and sound effects such as hearing auditory art multimedia elements; by static images and animations. Video and other dynamic pictures are composed of multimedia art space and time arts; sound and picture combination constitutes a visual art and interactive art. Multimedia combines a variety of art forms of media, with the artistic impact of the post-synthesis. Its visual arts, auditory arts, art integrated time and space are to express a rich audiovisual language, which played there color, light, image and sound complementary blend of aesthetic movement, so that works of art created tension.

\section{B. online media campaign generated rhythm control tempo beauty}

Movement rhythm is a multimedia works in demonstrations during dynamic performance. User during operation by regulating and controlling the speed can hold demo beats, or via automation systems, to obtain the beauty of rhythm and cadence. Once again, multimedia has presentations of visual communication interface. Visual interface is through a multimedia presentation on the user interface so that works are to achieve the presentation and communication of information. For example, the window arrangement in the form of the interface, the tool button icon image, display the menu, position the text, font, size and numbers, graphics, images and the use of color and other performance are reflected in its concrete. It is because there are numerous collections interface, also for multimedia works to constitute a huge visual communication system that allows the user to get a relatively large sensory satisfaction.

\section{Multimedia ART DEVElopMENT TRENDS}

Performance in the visual mass media forms change. Visual communication design is an art to communicate with people, carrying not only associated with visual communication design and the audience, more of a feeling relying sense and communication. Network already included among the paper, radio and television, and other mainstream media being. Internet is a new mass media, compared with the traditional media, with unlimited communication, information-rich, varied shapes convey, time-sensitive, interactive communication, to convey the effect of testability and low cost for the Visual Communication Design provides a good medium conditions. The rapid development of multimedia has been integrated into all aspects of public life. Multimedia art designer provides a new form of artistic expression and space, the more creative designers realize the unlimited potential, it is not only to bring about changes in the design process, but also is affecting the design style and way of thinking, to make it happen increasingly with a profound change in the fundamental transfer.

Performance in the online media and traditional media has "convergence" on

Morphological changes in principle from three concepts: co-evolution, convergence and complexity. "He explained that" convergence (convergence) is more like an intersection or marriage, the result is caused by a change in the convergence of each entity and creates a new entity. "This" new entity "is the result of a variety of media synergy survives," integration "has become one of the characteristics of multimedia history in the development of media forms has changed. For traditional media change is not a simple negation, and is a critical inheritance. 


\section{CREATIVE INSPIRATION OF MULTIMEDIA ART AND REFERENCE DESIGN TO EXPAND THE TRADITIONAL REALM}

Visual Communication Design has a close relationship with the media; the development of the media is in promoting the development of visual communication design. The emergence of online media visual communication design has changed from design to design-content form. But on the other hand, the same as in multimedia and traditional media, multimedia visual communication design with traditional visual communication also exists between continuity and unique design. Multimedia art remains a kind of visual communication based media art; therefore, studied visual communication design is bound to expand on the traditional media to multimedia. Multimedia design and visual communication design jointly owned traditional design elements with the basic principles of visual communication design, package including the principle of visual and text, graphics, images and colors and other design elements. It can be said, multimedia visual communication design is the traditional visual communication design in new media and new technology designed to support the creation of the new field of implementation, and visual communication design is the traditional inheritance and development.

\section{VISUAL COMMUNICATION DESIGN ELEMENTS INVOLVED IN THE PROCESS OF ONLINE MEDIA}

Due to the limitations of early speed and bandwidth, network media designers will take to facilitate the dissemination and smaller format image files (such as GIF, JPG format) to the rich web content. In recent years, there are remarkable achievements in building the information superhighway; people are no longer confined to simple web functions to achieve, to a higher level of artistic experience forward.

In general, there is more abstract visual communication design; this inevitable has contradiction and network media practicality. Embodies practicality convenience of online media in both early and late stage of technical feasibility, the designer works are to fully consider the balance in these two areas. If the blind pursuit of novelty, alternative, focus reflects the designer's subjective thinking, often because technical factors and environmental factors cannot be realized.

Due to the development of Internet technology appears in all aspects of dating phenomenon. It cannot be unified to determine the current level of technology division, but webbased media development perspective, is still in the web 2.0 eras. The main feature of this period is the importance of information to build mutual interaction mode. In this period, the amount of information of the Internet has been a geometric growth rate. Everyone is a consumer and producer of information, people cannot lead to a huge amount of information timely and accurate access to desired content, the search engines become the main tool for people to retrieve information, and rely on the steady demand of dominance web2.0 era. For designers, innovative ideas and design ideas should also follow the trend of the times, otherwise no matter how good visual effect once submerged in the vast sea of information, the same cannot be valued.

Online media visual communication design work has its own characteristics, which is no longer simply a flat graphic or web design work, in color, shape, etc. required to meet at the same time, interactive features are also key requirements. In Web2.0 technology framework, a visual communication design work is to meet the needs; we must also ensure compliance with the audience accustomed to the operation, such as the button, scroll mode, etc.

From the most intuitive point of view, humans are a "message" of animals, especially in terms of visual communication, the achievements of the human understanding of the world and they have the desire to control the world. However, the role of design itself, the appearance of performance is not the first one, but to provide information to the existence of high-quality visual reached entity; especially in the scope of application of the Internet economy and commodity society, the first purpose of the design is not to demonstrate the work itself, but it manifested goods. Given the existence of commodity necessity and value of design, in turn, it is designed to show the superiority and excellence of commodities through the art of goods to meet the needs of the people to achieve the purpose of a new life. Visual communication design network media also have service characteristics, such as a web browser software product is a good example: to serve viewers for achieving the subversion of the traditional products through art and design, thus changing people's habits.

Visual communication design has the general characteristics of the network media arts, but also the existence of their own artistic characteristics of clear theme. Internet media itself is a huge concept.

In the traditional form of the Internet, it continues to move closer to the process, there is incomplete evolutionary phenomena, which for the same period of transformation in terms of the designer, is a huge challenge. As there are different purposes, different subjects, different aspirations and so on. At the same time, visual communication design network media are related to social, cultural, economic, Internet technology, and many other factors, which can result in enormous aesthetic differences. If not able to do a clear theme, it is easy to fall into the design bottleneck; good network media visual communication design works and should be in line with the theme of the laws of logic, convenient viewer quickly absorb and understand, while in terms of visual elements contents constitute a reasonable process reflects the beauty of art. In other words, it is necessary to maintain the functional integrity of online media, as well as to highlight accompany artistry.

Complete idea. Visual Communication Design is an indepth online media behavior of graphic design, for graphic designers, the works of the greatest difficulty lies in the creative design and layout, and online media visual communication design in addition to the entire layout, but also for every depth processing modules. To the site, for example, any one site cannot consist of a single page, but by the overall structure of "father and son" relationship building, such as "tree", "T-type structure", "mouth-type structure" and 
so on. This structure is to establish contact through hypertext links, the parent page design is the basis for the sub-page design, including style, color, and other elements, the structure and must be taken into account.

\section{THE DISCUSSION OF WEB-BASED DISSEMINATION OF VISUAL COMMUNICATION DESIGN FEATURES}

Visual communication design of network media can also be interpreted as "visual communication design of the network environment," that this design behavior itself is with fast, convenient and extensive features. On this basis, if raising it to the art and design point of view, they have to grasp the following elements:

Internet media design is no longer limited to pictures and text. For our technical development of the Internet, the early designers was to balance sound, text, video and other interactive elements download, otherwise it will affect the user experience. Up to now, China has realized the fiber to the home; the bandwidth problem has been Internet media that is no longer a limiting form of disorder, the integrated use of a variety of media possible. Every form of media are appropriate to meet the needs of the viewer from visual, auditory, tactile, etc., while the emergence of virtual technology, people are more intuitive and interactive machine, not limited to a keyboard, mouse and other input devices.

From the formal point of view, there is a network of media and graphic design, visual communication design has a great difference: First, the formation process of online media are almost always done by computer equipment, no or very little need for drawing paper, ink, rulers and other tools. After the latter is in the form of long-term development and essentially unchanged, while the former because of the updated computer equipment, design software updating, monitoring or browser updating, will have a different response options. Secondly, manifestations of extremely rich network platform designers cannot require the viewer to use a fixed way or tools. Then, the viewer's personal preferences will cause different effects unified work.

The future development of visual communication design development proposals online media online media will inevitably move toward high degree of integration, these integration possibilities in addition to the maximum extent are to meet the needs of the viewer's visual outside, but also take into account the full portability of online media. This is because, if the fusion of online media is seen as a novelty then, it will include a variety of new media (two-dimensional animation, 3D animation, video format) form, as well as various applications technologies such as XML, Flash, RealAudio, etc. Such a large network of media convergence, if stranded on a technical level, they also lose the visual communication design necessary. In this regard, from a commercial point of view, it focuses on customer service, while weakening the platform technology that brings the bottleneck; on the other hand it can form different professional teams, the depth of mining resources and industrial customer segments. For example, the most common way is profitable online media advertising. Delivery person does not care how technology is implemented, they are only concerned with the ultimate benefits arising from, and through highly integrated nature of online media, which is clearly better than the general text, and pictures link ads more attractive, such as dynamic Flash by capturing the butterfly pop advertising information. In summary, visual communication, design of development of online media cannot be confined to their own property, which should also understand the value of their environment by changing their own ideas to circumvent of the lack of realization of the value and quality of design behavior change.

\section{CONCLUSIONS}

Computer network technology is in rapid development period, technological advances, changes in technology and methods are bound to affect the manifestation of visual communication design. Meanwhile, the visual design research of network media art belongs to convey design artistic disciplines and different ways of thinking and creative artistic point of view will produce different forms of art. Multimedia art and design completely break the traditional visual thinking of one-way, one-way characteristics, blur the boundaries of media design and between consumption, especially multimedia interactive qualities. Its purpose is to make information about the recipient who is also involved in the information design in the past, it has revolutionized the way of information exchange and as a result, the information is more rich, vivid and effective. In addition, multimedia art and design completely are closed state to break the traditional visual design that requires designers' comprehensive, threedimensional and integrated approach to understanding and grasp information of more creative, multi-dimensional with multi-space to organize this information. Therefore, multimedia design art design epitomizes the essence of art and science, art and technology high degree of integration; it will surely become a mainstream form of art and design future performance.

\section{References}

[1] Ge Bofei. Network media visual communication design research [D]. Hunan University, 2002.

[2] Jiang Yunsheng. Online media visual communication design study [J] Network Security Technology and Application, 2013,12: $120+122$.

[3] Cheng Shufen. On online advertising in visual communication design [D]. Central University for Nationalities, 2012.

[4] Sun Wei. Era of visual communication network design [J] Journal of Jilin College of the Arts, 2005,02: 41-46+ 71 .

[5] Yang Quanrong. Research and analysis of visual communication design visual space [D]. Xi'an Academy of Fine Arts, 2013.

[6] Duan Jian. Visual Communication Design online advertising research [D]. Hunan University, 2013.

[7] Ren Bin. Visual Communication forms and characteristics of modern digital media [D]. Xi'an Academy of Fine Arts, 2010. 